\title{
OPERATIONAL STORM SURGES FORECASTING IN AN ESTUARY
}

\author{
DENIS PARADIS ${ }^{1}$; PATRICK OHL ${ }^{1}$; PIERRE DANIEL ${ }^{1}$ \\ ${ }^{1}$ DPREVI/MAR, Direction de la Production, Météo-France \\ 42 Av Coriolis, 31057 Toulouse Cedex, FRANCE \\ e-mail: denis.paradis@meteo.fr ; patrick.ohl@meteo.fr \\ pierre.daniel@meteo.fr
}

\begin{abstract}
The numerical model Telemac-2D, based on the non-linear shallow water equations (depth integrated) and on the finite element approach, is used on the Gironde estuary. It is coupled to another larger scale operational storm surges model and forced by high resolution surface winds and pressure fields and by river run-off forecasts. The model has been calibrated during the 2007 summer on 10 selected cases which occurred during the last 25 years with important storm surges, and will be tested in real time from the 2007 autumn. It is expected to have an operational system for the 2007 winter, with a daily model run, for a $48 \mathrm{~h}$ forecast, and including the training of meteorologists and hydrologists who will have to use the model results, in a collaborative manner.
\end{abstract}

Keywords: operational forecasting; estuary; storm surge

\section{INTRODUCTION}

The 27th december 1999 a violent storm crossed the France with winds approaching $200 \mathrm{~km} / \mathrm{h}$ on the South-West coast and generated an exceptional storm surge in the Gironde estuary : around $1 \mathrm{~m} 60$ at Le Verdon, located at the entry of the estuary, the storm surge was amplified until it reached $2 \mathrm{~m} 60$ at Bordeaux, $100 \mathrm{~km}$ more inland. Several dykes were submerged, leading to severe floodings, especially in Bordeaux and on the site of a nuclear plant (Le Blayais, opposite to Paillac) which had to be stopped.

EDF/LNHE (Laboratoire National d'Hydraulique et Environnement, a department of Electricité De France's Research and Development Division) has then started studies to reproduce this phenomenum, to analyse it in order to better protect its power plant. In 20022003, with Météo-France, LNHE demonstrated the feasability of an operational suite which produced daily $48 \mathrm{~h}$ forecasts of the Gironde sea level by the mean of an hydraulic model.

In 2003, the DE (Direction de l'Eau, the state agency in charge of the hydrology in France) attributed the responsability of the sea level forecasts in the Gironde estuary to the SPC-LA (Flooding Forecast Service on the Atlantic Coastline). In 2004, the DE and MétéoFrance agreed to launch a project with the objective of setting up an operational system able to predict the sea level on the Gironde estuary, including the LNHE hydraulic model, its input 
data, a post-processing and the organization of the meteorologists and the hydrologists involved in the forecast. SPC-LA is the contracting authority whereas Météo-France is the prime contractor. Around 4 year.man were affected to this project.

In the end of 2005, the DE, Météo-France, EDF-LNHE and CETMEF signed an agreement to define the contribution of each partner to bring into operation the hydraulic model of the LNHE. The objective is now to have a complete operational system ready before the end of 2007.

\section{METHODOLOGY}

MODEL

We use the numerical model Telemac-2D, solving the Shallow Water Equations (also called Saint-Venant) in the non-conservative depth-velocity form. This model was developed by the LNHE, it is based on the finite element theory (Hervouet and Van Haren, 1996). A twodimensional solver will compute the free surface elevation and the depth-averaged velocity vector in the domain. The main features of TELEMAC-2D that are used in this system are : propagation of long waves, taking into account non-linear effects ; bed roughness represented by using the Strickler law ; influence of meteorological factors (atmospheric pressure and surface wind) ; turbulence ; torrent and river flows ; dry areas in the computational domain (inter-tidal flats).

The unstructured grid consists of some 12837 triangular elements of varying sizes and shapes and 7350 nodes. The triangular elements' size ranges from 5 kilometres over ocean to 50 metres over rivers. The limits of the domain in upstream sections of the 2 rivers (Dordogne and Garonne) were chosen at such distance from sea as to make marine influence (tide) sufficiently weak. The oceanic boundary ( $25 \mathrm{~km}$ off shore) coincides with specific grid points of the Météo-France operational storm surges model and with an area of rather smooth bathymetry.

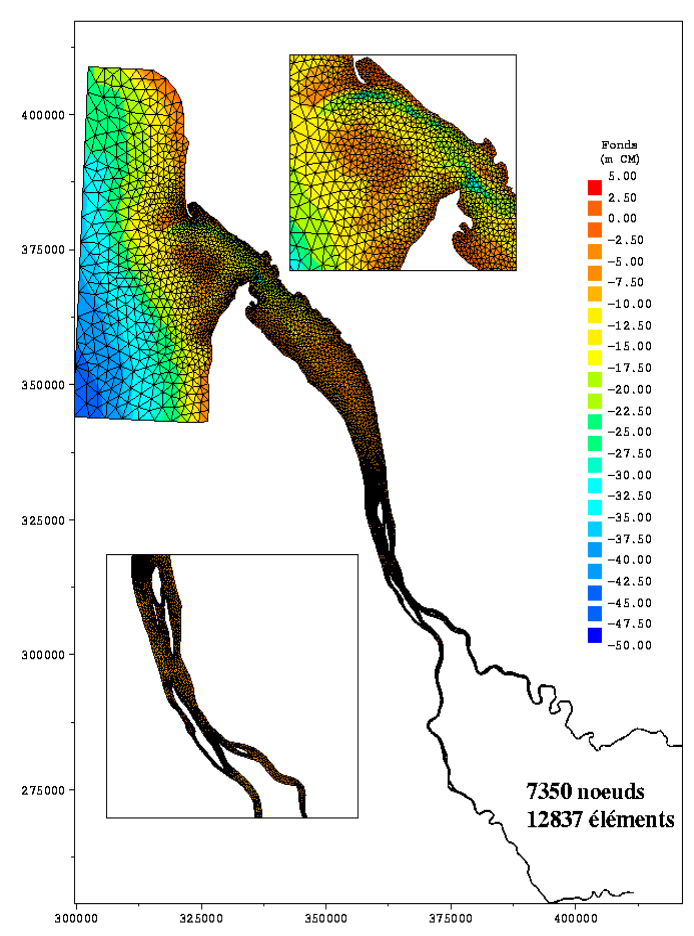




\section{FIGURE 1 : GRID AND BATHYMETRY OF THE GIRONDE MODEL, DESIGNED PAR}

EDF/LNHE.

The bathymetry was built by LNHE from several sources (SHOM, Port Autonome de Bordeaux, SN de la Garonne et de la Dordogne) whose measurements date from 1985 to 2000.

\section{DATA FLUX}

As illustrated on the FIGURE 2, the model is coupled to another larger scale operational storm surges model (Daniel, 2001) and forced by high resolution surface winds and atmospheric pressure fields (from the Aladin model (Joly, 1992) nested in the Arpege model (Courtier et al, 1991)), by river run-off forecasts and by the foreseen height and current of tides at the oceanic boundary. All these data are, once a day, prepared by the appropriate service and operationally provided to the model which will be launched daily, for a 48 hours forecast. Meteorological forecast conditions are provided with hourly time step data for the 12 first hours of the model integration and with $3 \mathrm{~h}$ time step data thereafter. The rivers flows are computed for the 6 first hours and considered as constant after.

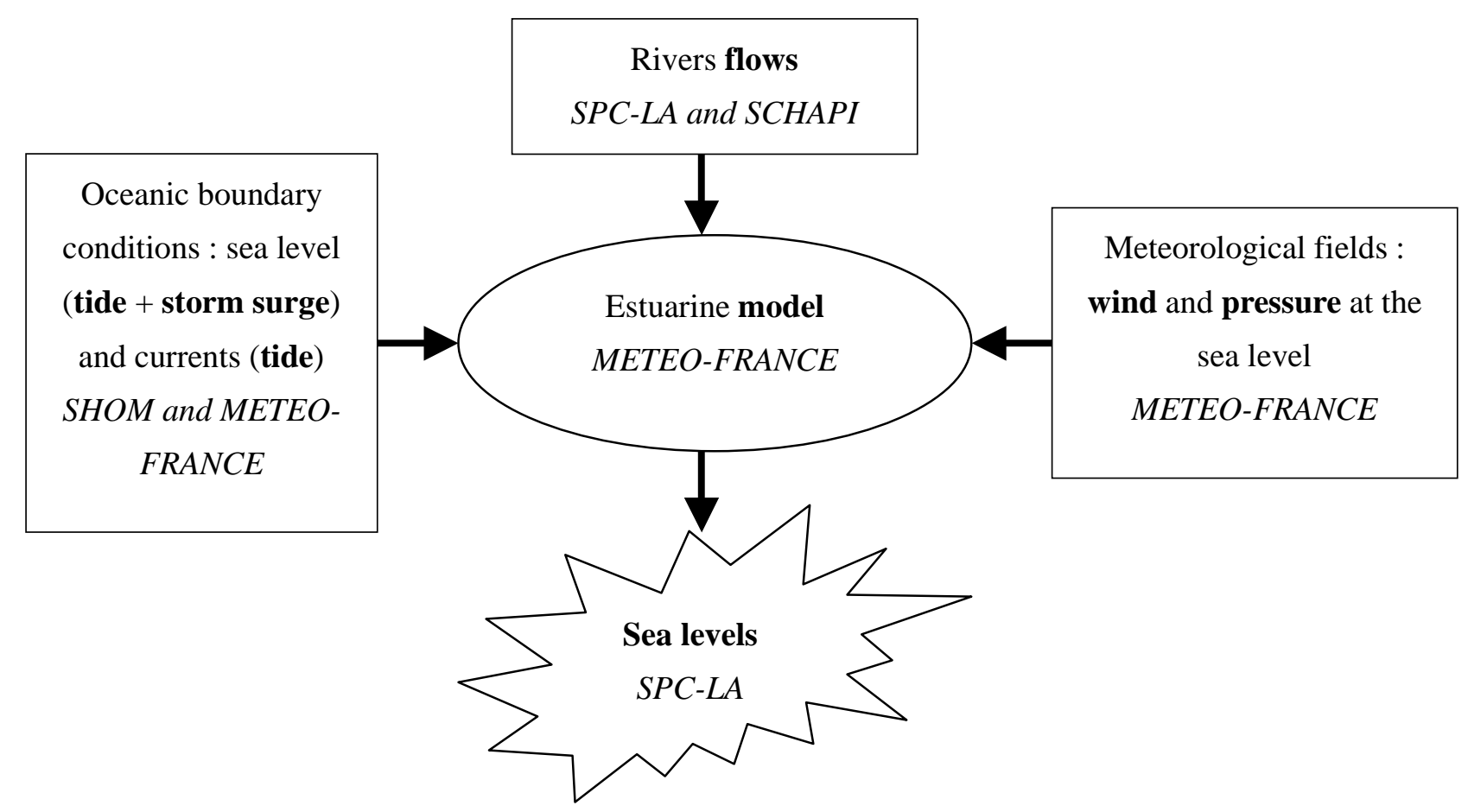

FIGURE 2 : OPERATIONAL DATA FLUX FEEDING OR GENERATED BY THE ESTUARINE MODEL. EACH ORGANISM RESPONSIBLE OF A COMPONENT IS INDICATED IN ITALIC. 


\section{MODEL CALIBRATION}

First, 10 events associated with very high sea levels on the Gironde estuary which occurred during the last 25 years, have been selected. Every risk sources have been covered : spring tides, strong river run off and violent winds. The data of 11 tide gauges along the estuary and the rivers have been controled and corrected when possible. A study also isolated the non-overflowing periods during the 10 events : as the model doesn't take account of the overflows (option too expensive in computation resources for an operational system with time constraints), it was important to compare its results with appropriate observations (without or before an overflow, or on a location where sea level is not influenced by overflows).

Then, the model configuration used by LNHE in 2002-2003 has been evaluated on the 10 selected events : if the results were satisfactory from the ocean to the mid-estuary, the area for which the model have been primarily built (EDF power plant protection), they became less and less correct when they were compared with upstream tide gauges. At Bordeaux for the selected event in 2003, for example, the sea levels were reproduced with phase differences comprised between 20 and 40 minutes in advance and high (resp low) tide errors around +40 $\mathrm{cm}$ (resp $-60 \mathrm{~cm}$ ). The tidal range in this case was about $4 \mathrm{~m}$. The model needed so to be calibrated again, on the whole domain.

The space-dependent Strickler coefficient (ranging from 70 in the ocean to 60 in rivers, in the first configuration of the model), will be calibrated again on the 4 selected events without significant overflows. The calibration will consist in varying the Strickler coefficient (by steps of \pm 5 units) uniformly over the domain and then, for each variation, in running the model. A criteria will be built from the model errors computed with the tide gauges data on the 4 events. The Strickler coefficient on the downstream area (the oceanic one) which gives the best results will be kept. The same procedure will be applied again to determine the Strickler coefficient on the next upstream area, until the river boundary is reached (4 areas at all). The calibration work will be done during the 2007 summer.

\section{RESULTS}

\section{IMPLEMENTATION AT METEO-FRANCE}

First, an operational data base was built and is currently feeded by tide gauge measurements (operated by the Port Autonome de Bordeaux and provided an update every quarter of an hour) and the data flux, presented above, was implemented. Then, the operational computing facilities of Météo-France have been hosting the pre-operational system since July 2007. The well tuned configuration of the model being not yet available, a preliminary configuration is used, in order to prepare the future environment of the operational system. So, daily, the model starts running at around $3 \mathrm{~h} 30 \mathrm{UTC}$ when data become available. First, an analysis is computed for the whole day before, from the meteorological analyses and the river run off observations. Then the model is integrated in a forecast mode, using the final state of the previous analysis run as its initial state. The sea- 
level forecast is computed for the 48 next hours from 0h UTC of the current day. The model run on a linux cluster of scalar processors (Xeon Intel, 3.2 GHz). A 24 hours integration takes around 25 minutes elapsed.

The capability of the system to deliver results in case of degraded environment has been searched. For example, when some forcing data are lacking, the system will automatically try to replace these data by others.

The post-processing of the model results consists in 3 tasks. The first one transcribes the results in an appropriate format and put them in the Météo-France operational data base. The forecaster will then be able to use its standard visualization tool to get the model results displayed out of all other usual data (atmospheric and waves models ; tide gauges, satellite and radar observations...). Another task computes daily scores (automatic control of the day before results) by comparison with the available observations. These scores will allow the forecasters to supervise the model behaviour regularly and, in a delayed mode, to start studies on the badly reproduced events. The last task updates a web site which presents the model results and its scores. This will also represent a relief tool for the forecasters and permit them to have, by means of internet, a look on the sea-level forecasts when they are away of their office.

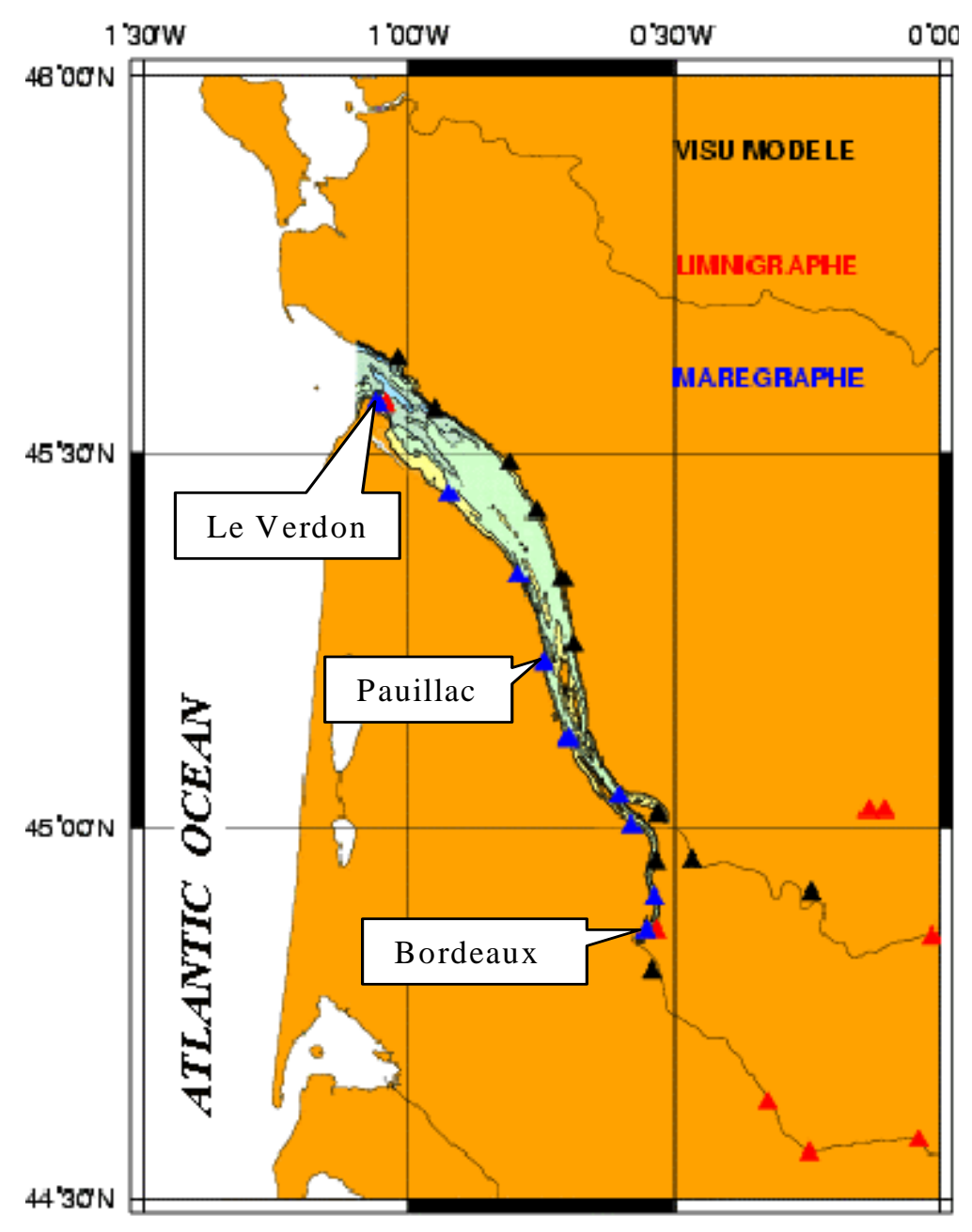



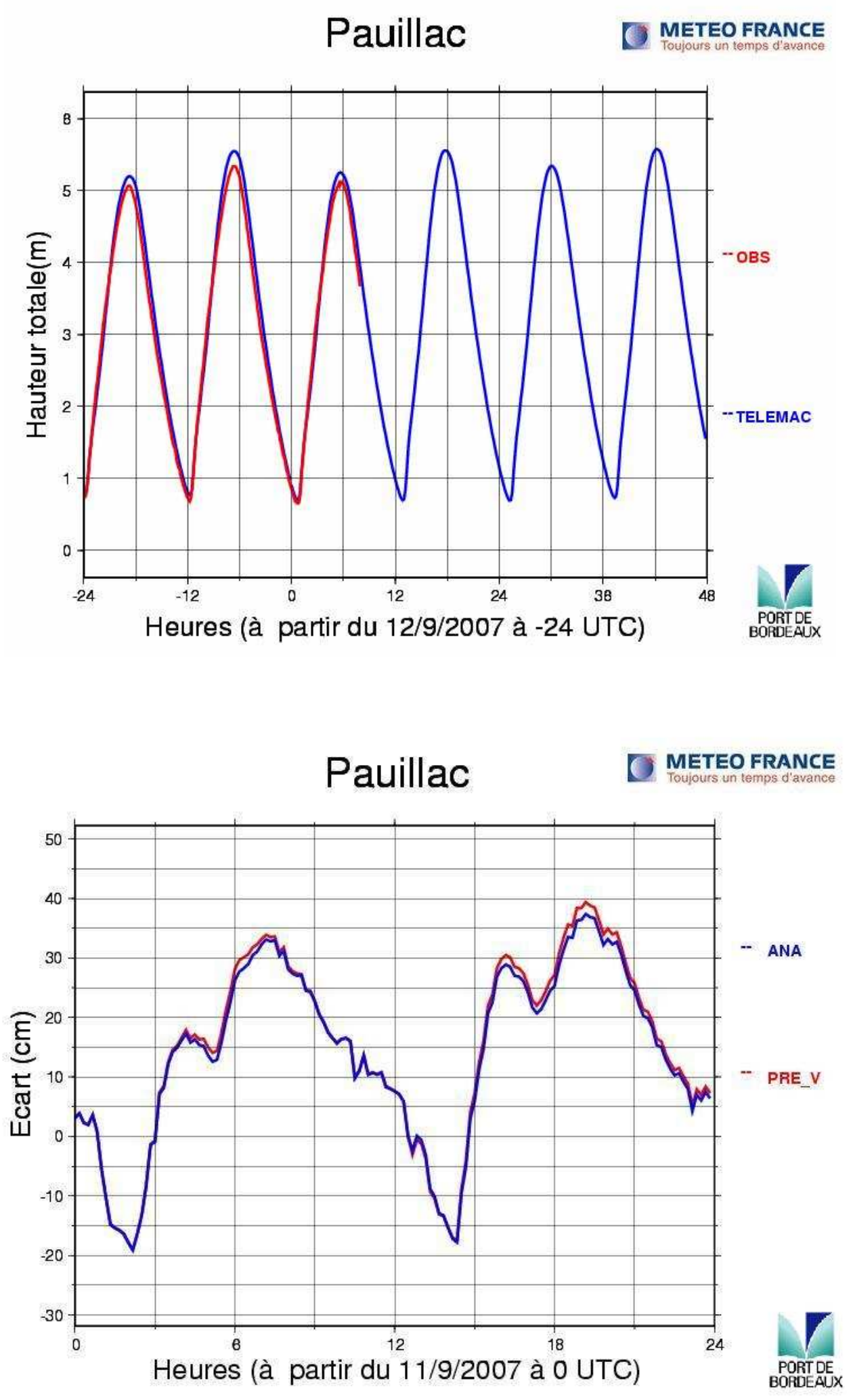

FIGURE 3 : EXAMPLES OF THE OUTPUTS PROVIDED BY THE WEB SITE : ABOVE : DIFFERENT LOCATIONS OF THE OUTPUTS (WITH OR WITHOUT TIDE GAUGES) ; MIDDLE : SEA LEVEL FOR THE PREVIOUS 24 H (ANALYSIS) AND PREDICTED FOR 
THE NEXT 48 H AT PAUILLAC THE 12 SEPTEMBER 2007 (MODEL RESULTS IN BLUE AND AVAILABLE OBSERVATIONS IN RED) ; BELOW : MODEL ERROR AT PAUILLAC ALONG THE 11 SEPTEMBER 2007 (ANALYSIS IN BLUE AND FORECAST 0-24H DONE THE DAY BEFORE IN RED).

\section{OPERATIONAL USE}

Hydrologists and meteorologists belong to two distincts communities with their own competence, vocabulary and tools. However, the sea level forecast requires to merge their respective know-how and to well define what each specialist have to bring in the process to obtain a detailed expertise. The Gironde project allowed them to better know each other and this will be completed by a common training on the system. The operational visualization tool is also shared by each actor to make dialogue easier. They agreed upon the information the meteorologist will prepare daily to permit hydrologists to interpret and adapt the model results. In particular, the meteorological forcing, used by the hydaulic model, will be assessed and the weather forecaster will provide the hydrologists with his expertise (example : storm conditions will happen with a 2 hours delay, will be $15 \%$ more intense but slightly northward).

Before the operational use (winter 2007), the sensitivity of the model results to the wind (direction and intensity) and to the river run-off will be studied. This will give the means to correct the model results from the remarks about the errors on the forcing data (meteorologist and hydrologist expertise).

\section{CONCLUSION}

During the past, the Gironde estuary has experienced severe storms which showed how vulnerable to the flooding was this region. To reduce the social and economic impact of these natural disasters, the national civil security agencies expect skilled warnings, at time. The future operational storm surge forecasting system has been built with this aim and it will include a validated model, a reliable data flow (tide gauge observations and forecast results from atmospheric or hydrologic or oceanic models), a visualisation tool, an effective collaboration between weather forecasters and hydrologists to determine daily the sea level and eventually to warn the national authorities against a flooding.

It is expected to have an operational system ready for the 2007 winter. However, the first version of the model will take advantage of the regular computation of its scores to study the discrepancies with the observations and to try to improve the model (bathymetry update, boundary conditions...). Moreover, the role of the waves will be taken into account in the future, because its impact could be essential. The overflow areas should also be represented as soon as the computing resources and the topography data become available.

\section{ACKNOWLEDGEMENTS}


The DE (Direction de l'Eau with its two specific services, SCHAPI and SPC-LA), the CETMEF (Centre d'Etudes Techniques Maritimes Et Fluviales) and EDF/LNHE are thanked for their contribution towards the ambitious Gironde project launched by the DE and MétéoFrance.

\section{REFERENCE}

1. J. M. Hervouet and L. Van Haren, Recent advances in numerical methods for fluid flow, chapter 6 of Floodplain processes, Editors Anderson M.G., Walling D.E. and Bates P.D. Wiley \& sons (1996).

2. Daniel P., P. Josse and V. Ulvoas, 2001: Atmospheric forcing impact study in MétéoFrance storm surge model, Coastal Engineering V, Computer modelling of seas and coastal regions, WIT Press, pp 135-144.

3. A. Joly, ARPEGE/ALADIN adiabatic model equations and algorithm, internal note of Météo-France (1992).

4. Courtier, P., C. Freyder, J.-F. Geleyn, F. Rabier and M. Rochas: The ARPEGE project at Météo-France. Proc. of the ECMWF Seminar on Numerical Methods in Atmospheric Models , Vol. II, ECMWF, Reading, England, pp. 192- 231, 1991. 